\title{
Development and Field Evaluation of a
}

\section{Low-Cost Wireless Sensor Network System for Hydrological Monitoring of a Small Agricultural Watershed}

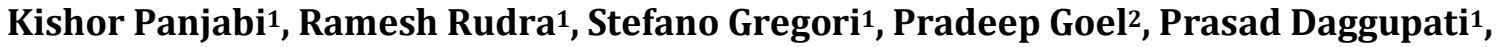 \\ Rituraj Shukla1, Balew Mekonnen' ${ }^{1}$ \\ ${ }^{1}$ School of Engineering, University of Guelph, Guelph, Canada \\ ${ }^{2}$ Environmental Monitoring and Reporting Branch, Ontario Ministry of the Environment, Etobicoke, Canada \\ Email: kpanjabi@uoguelph.ca
}

How to cite this paper: Panjabi, K., Rudra, R., Gregori, S., Goel, P., Daggupati, P., Shukla, R. and Mekonnen, B. (2018) Development and Field Evaluation of a Low-Cost Wireless Sensor Network System for Hydrological Monitoring of a Small Agricultural Watershed. Open Journal of Civil Engineering, 8, 166-182.

https://doi.org/10.4236/ojce.2018.82014

Received: January 31, 2018

Accepted: June 18, 2018

Published: June 21, 2018

Copyright $\odot 2018$ by authors and Scientific Research Publishing Inc. This work is licensed under the Creative Commons Attribution International License (CC BY 4.0).

http://creativecommons.org/licenses/by/4.0/

(c) (i) Open Access

\begin{abstract}
Hydrological monitoring and real-time access to data are valuable for hydrological research and water resources management. In the recent decades, rapid developments in digital technology, micro-electromechanical systems, low power micro-sensing technologies and improved industrial manufacturing processes have resulted in retrieving real-time data through Wireless Sensor Networks (WSNs) systems. In this study, a remotely operated low-cost and robust WSN system was developed to monitor and collect real-time hydrologic data from a small agricultural watershed in harsh weather conditions and upland rolling topography of Southern Ontario, Canada. The WSN system was assembled using off-the-shelf hardware components, and an open source operating system was used to minimize the cost. The developed system was rigorously tested in the laboratory and the field and found to be accurate and reliable for monitoring climatic and hydrologic parameters. The soil moisture and runoff data for 7 springs, 19 summer, and 19 fall season rainfall events over the period of more than two years were successfully collected in a small experimental agricultural watershed situated near Elora, Ontario, Canada. The developed WSN system can be readily extended for the purpose of most hydrological monitoring applications, although it was explicitly tailored for a project focused on mapping the Variable Source Areas (VSAs) in a small agricultural watershed.
\end{abstract}

\section{Keywords}

Wireless Sensor Network, Low-Cost, Hydrological Monitoring, Real-Time 
Data Collection, Agricultural Watershed

\section{Introduction}

Long-term, high-quality climatic and hydrological data are essential for hydrological research and the implementation of effective water management strategies at both field and watershed scale. Monitoring and collecting long-term data from remotely located watersheds are time-consuming and expensive; due to the need for frequent visits to the sites for maintaining and monitoring the instruments and for data collection [1]. Though this approach involves a significant amount of time and resources; it is imperative and valuable. Currently, a number of data acquisition technologies are being used to obtain hydrological data. Accuracy, resolution, and scalability are some of the significant issues that need to be addressed in developing an efficient and robust hydrological monitoring system [2] [3]. In the earlier techniques, analog type network with cables and a number of sensors wired to data loggers were used for hydrological monitoring. The need for cabling in the field increases costs and restricts the spatial size of the monitoring area [4] [5], whereas the digital wireless networks can be deployed to collect long-term data at larger scale and resolution while maintaining robust and reliable network performance [6] [7] [8].

In recent years, the rapid development of WSN technology has created new opportunities for sensing, computing, and communication in a wide range of applications in the field of science and engineering. WSNs integrate real-time sensing, computing, and communicating processes and provide an efficient and cost-effective observation technique, monitoring, gathering data, performing local computations and relaying the aggregated data capabilities [9] [10].

WSNs comprise of few to several "nodes" (known as a Mote in North America) where each node is connected to one or more sensors [11]. Each sensor node has four key components: 1) the microprocessor \& ADC (analog to digital converter), 2) transceiver \& antenna, 3) memory unit, and 4) external sensors [12]. The individual sensor node consists of a number of hard-wired sensors. Each node is wirelessly connected to other nodes, and finally to a central base station (Figure 1). A digital WSNs comprised of spatially distributed nodes connected to sensors communicates bi-directionally to the central location [13]. As WSN does not require cables, they are cheaper and easier to install, in addition to requiring low maintenance. Flexibility, easy and rapid deployment, self-organization, high sensing reliability, and low-cost characteristics of WSNs make them a promising technology for various applications [14] [15].

WSNs can be used with many diverse types of sensors, such as thermal, optical, acoustic, seismic, magnetic, infrared, pressure and radar [16]. Sensors used in WSNs convert physical parameters like temperature, soil moisture, pressure, light, speeds, etc. into a signal and measure them electrically [17]. These sensors 


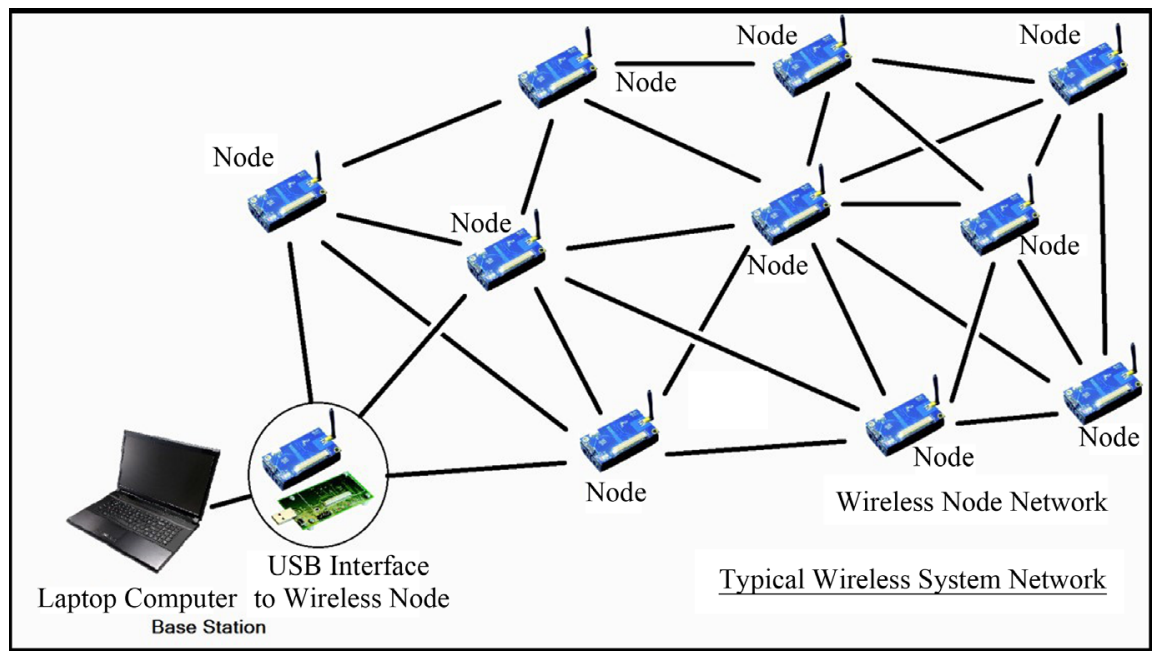

Figure 1. A typical distributed wireless sensor network system.

can monitor a wide variety of conditions such as temperature, pressure, humidity, light, noise level, movement, speed direction and size of an object [18] [19].

The widespread adoption of these devices, particularly for industrial applications, has made them extremely cost-effective [19] [20]. Sensor nodes can be used for different purposes, including event detection, continuous tracking, location sensing, etc. [21] [22] [23]. Currently, WSNs are extensively used in many real-world applications like security and surveillance, home and industrial automation, automobiles, medical applications, fire and pollution monitoring, flood forecasting, habitat monitoring, military applications, and hydrologic and environmental monitoring [24] [25] [26]. Recently, agriculture monitoring has attracted considerable research attention, and WSNs are emerging as a great aid in the field of precision agriculture to improve crop quality, productivity, and resource optimization. It is also widely used in greenhouses for monitoring and controlling humidity, temperature, moisture water flow, etc. [27] [28].

Unlike other systems, WSNs are designed for specific requirements and applications [29]. The WSNs for environmental monitoring are specially designed to collect the data on an event-driven or time-driven basis according to environmental conditions and application requirements, i.e., when a specific environmental event occurs or at the particular time interval [30]. Details of importance, the accuracy of the data and the physical environment of deployment require careful consideration in designing the WSN system. The WSNs must be designed to withstand weather conditions, such as temperature, winds, rain, snow, and pressure or vibration [7]. Although WSN technology is continuously improving, no off-the-shelf solution exists yet for hydrological monitoring applications [31].

The WSNs also have various resource constraints and challenges. Constraints include energy, bandwidth, memory, and processing capacity. Among them, energy consumption is of prime importance as each sensor node based on the 
number and type of the attached sensor components relies on the limited availability of battery power for data collection, processing, storage, transmission, and reception [32]. Moreover, energy consumption rate of each node depends on its distance from Base Station. The inequality of energy usage among the sensor nodes in the network affects the lifetime of the network for the intended application [33] [34]. Careful energy resource management is crucial for the WSNs deployed in remote areas for an extended period. Another specific challenge to WSN is the security attacks from the surrounding deployment area due to the broadcast nature of radio transmission. Due to the limited computing power of nodes, it is difficult to provide security and to protect the sensitive data from unauthorized access to WSN using public-key cryptography [35]. The climate and deployed environment also affect the efficiency in the WSN [36].

This study aimed to develop a WSN system to monitor and collect the real-time hydrological and climatic data for the research study of mapping and modeling Variable Source Areas from a distantly located watershed. The specific objectives were to design and deploy a long-term, low-cost, and robust WSN system that can withstand harsh climatic conditions (extreme variation in temperature, high winds, rain, and snow) of humid and temperate climatic conditions such as Southern Ontario, Canada.

\section{Materials and Methods}

\subsection{Design and Development of WSN}

The design and development of the WSN took place over a four-year period from 2007 to 2011 [37]. During this period, a number of WSNs with different types of components were used, and designed systems were rigorously tested in lab and field conditions. Various design and deployment issues were identified and resolved during the development of the WSN.

The WSN development was conducted in three phases. In the first phase, a WSN system was designed using hardware from Texas Instruments (TI). The nodes were based on TI-MSPTRF6903 boards with a TRF6903 RF-transceiver and an MSP430 microcontroller. The transceiver operates in the $902-\mathrm{MHz}$ to 928-MHz ISM frequency band, and the microcontroller was a 16-Bit ultra-lowpower MCU with $60 \mathrm{kB}$ of Flash memory for data storage. Soil moisture sensors ICT ECH2O-20 cm of Decagon Devices, Inc. were used. The MPXV70002 vacuum pressure sensors from Freescale were used to capture the water height and were connected to the Analog to Digital Converter (ADC) port of the TI board. The board was programmed via the MSP430 JTAG connector. The Multipoint Control Unit (MCU) Flash memory was erased and reprogrammed. The IAR System's Workbench EW430 software package, in combination with the MSP430 JTAG, allowed real-time debugging of the code. The developed WSN with three nodes was tested and evaluated in the laboratory and the field; however, it was observed that the system was consuming immense power. Moreover, 
the communication range of the nodes was limited, and the wireless communication was sensitive to metal fences and electrical power lines. These problems caused noise in temperature and pressure readings [38] [39].

In the second phase, the WSN system was modified to resolve the shortcomings encountered in phase 1 . In the new version, the hardware components from Crossbow (Xbow) were used to build a new WSN system. Crossbow's wireless sensor network was based on XM2110 nodes with built-in control and communication functions. Each platform included an ATmega1281 low-power microcontroller with a 10-bit ADC and $512 \mathrm{kB}$ of memory and an AT86RF230 RF front-end IEEE 802.15.4 compliant, and a ZigBee transceiver with $300 \mathrm{~m}$ line-of-sight transmission range. The network gateway consisted of an IRIS mote connected to a USB MIB520CA interface. Motorola MPXV7007DP Pressure sensor and the ICT ECH2O-20 cm soil moisture sensor were attached to the 51-pin expansion slot through a printed circuit board (PCB). The interface board passed the sensor data onto a PC. The nodes were powered by using two 2.4 V-750 mAh AAA Duracell NiMH batteries.

The software tool Mote-View [40] was used which is designed specifically for the WSNs, uses XML files to convert the data from simple binary input-form from the gateway into decimal values, and these values could be displayed in real-time and saved in a database. The program allows database dumping, whereby collected sensor data is exported into a text file. The text file can be read in Excel and modified with custom calibration equations. The modified WSN system was tested in the lab as well as in the field for communication between nodes and also between the nodes and the gateway. The range of the node as per the Crossbow IRIS reference manual was $300 \mathrm{~m}$ for outdoor conditions and 50 $\mathrm{m}$ for indoor situations. The transmission range of the nodes in the field was found to be about $250 \mathrm{~m}$ at the optimal battery voltage, with the range decreasing in accordance with drops in the battery voltage. This system was installed in the study watershed at the Guelph Turfgrass Institute of the University of Guelph, where it performed satisfactorily under a small height of vegetation and flat ground surface conditions. The study watershed was monitored, and the data for modeling the spatial variability of runoff generating areas were collected from July 2008 to April 2009.

Despite successful application of this WSN system, it still required further improvements due to its short battery life and interruption of the signal from depressions and tall vegetation. The battery life was measured to be 11 days with the original configuration. The deployed solar ESS unit proved to be the most effective system as it correctly functioned over a testing period of 32 days without completely dissipating the battery power. The disadvantage of this system was that the large size of the node board required a sizeable waterproof housing unit and an extended antenna which was challenging to maintain in the field [39].

Taking these issues into consideration, the WSN system was further modified 
in phase 3, with the objective of improving the efficiency. For further improvement of the WSN system, an updated third generation MICA2 IRIS $2.4 \mathrm{GHz}$ nodes XM2110CA were used (Figure 2(1)). This node featured several new capabilities that enhanced the overall functionality of the WSN system. The communication range of this node was twice than the previous node and a built-in 1.2-inch monopole antenna. A PCB was designed and fabricated in the department lab with the capacity to connect a maximum of six different kinds of sensors to the 51-pin expansion slot. The interface unit MIB510CA, shown in Figure 2(2), allowed the user to reprogram any node by plugging the node directly into the base and operating it as a part of the root node interface, giving the PC a data conduit of the radio-based sensor network.

\subsection{Sensors}

The pressure sensor used for the phase 3 WSN system shown in Figure 2(3) is a new series of sensor called the Freescale MPXV7007DP. The MPXV7007DP is a piezo-resistive monolithic silicon dual port pressure sensor. It has an output range of $(-2)$ to $2 \mathrm{kPa}$ with an accuracy of $\pm 2.5 \%$, with 0.5 to $4.5 \mathrm{~V}$ proportional output voltage. The operating temperature range for this sensor is $-40^{\circ} \mathrm{C}$ to $125^{\circ} \mathrm{C}$. The (E240-40761 10HS) $10 \mathrm{~cm}$ long (Decagon Devices, Inc.), highfrequency soil moisture sensor (Figure 2(4)) was selected for monitoring soil moisture. This capacitance type sensor has a large sphere of influence to measure the dielectric permittivity of the soil accurately. The Volumetric Water Content (VWC) measurement range of the $10 \mathrm{HS}$ sensor is $0 \%-57 \%$ for operating temperature between $0{ }^{\circ} \mathrm{C}-50^{\circ} \mathrm{C}$ with an accuracy of $\pm 0.02 \mathrm{~m}^{3} / \mathrm{m}^{3}( \pm 2 \% \mathrm{VWC})$ in any soil. The electric circuit inside the 10HS changes the capacitance measurement into a proportional millivolt $(\mathrm{mV})$ output. The high-frequency oscillator

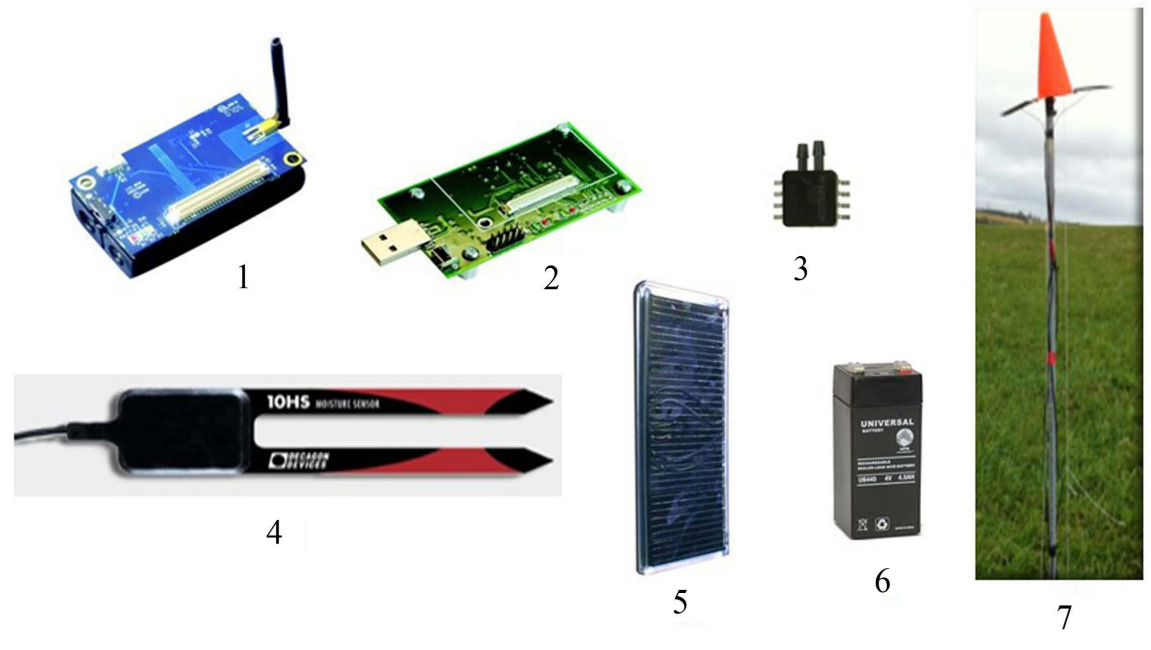

Figure 2. IRIS Mote XM2110CA (1) gateway unit MIB510CA (2) pressure sensor. "Freescale" MPXV7007DP (3) soil moisture sensor (E240-40761) 10HS (4) 6V DC 100 mA solar panel (5) $4.0 \mathrm{~V}$ (4.5 Ah) lead-acid battery (6) assembly of a node in the field (7). 
removes the soil type sensitivity of the sensor and thus, improves its ability to measure soil moisture in any soil.

\subsection{Power Supply}

The third generation MICA2 nodes require a power range of 1.7 to $4.3 \mathrm{~V} \mathrm{DC}$ supply for communication within its wireless network. After rigorous testing of various conventional and rechargeable batteries, $4.0 \mathrm{~V}$ ( $4.5 \mathrm{Ah})$ lead-acid batteries were found to be the most reliable for this application. These batteries lasted for about 30 days in the field under normal climatic conditions (Figure 2(6)). Solar panels of $14 \times 4 \times 0.5 \mathrm{~cm}$ with $6 \mathrm{~V}$ DC open circuit voltage and a short circuit current output of $100 \mathrm{~mA}$ were used to recharge the batteries. These panels have two solder tabs with $7.5 \mathrm{~cm}$ long insulated leads to be connected to the batteries and weigh only $27 \mathrm{~g}$. Each WSN node was provided with two solar panels to charge the batteries and maintain the supply voltage within a specified range to extend the battery life and the WSN operation, as shown in Figure 2(5).

\subsection{The Sturdiness of Node Assembly}

Each wireless node was housed in a sturdy and watertight PVC housing $(80 \times 50$ $\times 25 \mathrm{~mm}$ ) to withstand harsh temperatures, winds, and rain in the field. Moisture absorption packages were also placed within the casing to prevent humid conditions and to ensure that moisture does not collect on the electronics. The node housing was attached to a $3.0 \mathrm{~m}$ long and $25 \mathrm{~mm}$ diameter PVC pipe. This pipe was connected to a $450 \times 450 \times 100 \mathrm{~mm}$ wooden pedestal.

The wooden pedestal was secured in the field using four $29 \mathrm{~cm}$ long PVC plugs. A glow sign cone was attached on top of the node to protect the PVC housing from rain, snow and for providing prominent visibility (Figure 2(7)). A pair of solar panels was attached to this cone. This modified node setup was found to be very sturdy and resistant to severe weather conditions. The overall node components, sensors, and node assembly in the field are shown in Figure 2(7).

\subsection{Communication Connectivity}

The nodes were elevated $3.0 \mathrm{~m}$ above ground level to increase communication connectivity so that the crop height and the depressed areas did not interfere with the line of sight connectivity between the nodes. Increased height of the nodes improved connectivity between the nodes and resulted in a decreased number of required nodes and reduced the overall cost of the WSN system. The hardware components were purchased directly from the distributors, and data acquisition boards for the IRIS Mote were designed and fabricated in the laboratory in order to increase the cost-effectiveness. The assembling of WSN components was carried out in the department workshop. A summary table listing the main characteristics of the three phases of WSN development is shown in Table 1. 
Table 1. Summary of main characteristics of the three phases of WSN development.

\begin{tabular}{|c|c|c|}
\hline $\begin{array}{l}\text { Development of } \\
\text { WSN system }\end{array}$ & Hardware used & Main characteristics of the system \\
\hline Phase 1 & $\begin{array}{l}\text { Node: TI-MSPTRF6903 } \\
\text { SM Sensor: ICT ECH2O } \\
\text { P. Sensor: MPXV70002 }\end{array}$ & $\begin{array}{l}\text { - Limited communication range } \\
\text { - Communication sensitive to metal fences and } \\
\text { electrical power lines } \\
\text { - } 60 \mathrm{~kb} \text { of node memory } \\
\text { - Noise in temperature and pressure readings } \\
\text { - Higher power consumption } \\
\text { - Moderate communication range }(250 \mathrm{~m})\end{array}$ \\
\hline Phase 2 & $\begin{array}{l}\text { Node: MICAz } 2.4 \mathrm{GHz} \\
\text { SM Sensor: ICT ECH2O } \\
\text { P. Sensor: MPXV70002 }\end{array}$ & $\begin{array}{l}\text { - Communication interrupted by depressions } \\
\text { and crop height } \\
\text { - } 512 \mathrm{~kb} \text { of node memory } \\
\text { - Higher power consumption }\end{array}$ \\
\hline Phase 3 & $\begin{array}{l}\text { Node: MICA2 IRIS } 2.4 \mathrm{GHz} \\
\text { (XM2110CA) } \\
\text { SM Sensor: E240-40761 - 10HS } \\
\text { P. Sensor: MPXV70002 }\end{array}$ & $\begin{array}{l}\text { - Satisfactory communication range }(500 \mathrm{~m}) \\
\text { - } 3^{\text {rd }} \text { generation tiny wireless platform for smart } \\
\text { sensors } \\
\text { - } 512 \mathrm{~kb} \text { of node memory } \\
\text { - Low power consumption }\end{array}$ \\
\hline
\end{tabular}

\subsection{Data Visualization Tool for WSN}

The Mote-View interface software developed by Crossbow is an open source tool for operating and visualization of WSN systems. It allows users to operate, monitor and visualize the various functions and status of the WSNs. Each node collects data through its sensors and transmits it to the base station. The data packets received by the base station are stored in the connected computer. MoteView uses XML files to convert the data from its simple byte input form into the decimal values in the base station. These values are displayed in real-time in a window and saved in a database. The program allows for database dumping which exports the collected sensor data into a text file. The text files can be tabulated and read into Excel and modified with custom calibration equations. The Mote-View interface has four main tab sections. The toolbar tab allows the user to specify activities and initiate various commands. The second tab displays the list of the nodes, their health, and deployment status. The third visualization tab has four sub-tabs and shows the sensor data as data view, command view, chart view, and topology view. The fourth server tab shows incoming messages and a $\log$ of the events.

\section{Results and Discussion}

\section{Laboratory Calibration of Nodes}

The calibration of soil moisture and pressure sensors was performed in the laboratory. Three sensors from a group of sensors were randomly selected for calibration. The soil from the experiment field was used to calibrate the soil moisture sensors. An oven dry soil with a bulk density similar to field conditions was packed into multiple containers. The soil was evenly packed in the containers, and the sensor was inserted into the container during the packing of the soil. The sensor reading was noted, and the volumetric water content ( $\theta$ \% by volume) of 
the soil sample was determined using the gravimetric method. Water was added to the container; the sensor reading was recorded, and water content was measured again. This procedure was repeated until the saturation of soil was achieved.

The data obtained from the sensor reading and soil water content were plotted as shown in Figure 3. The following equation fitted to the data with a determination coefficient R2 of 0.9299 .

$$
\theta y=0.001 x^{2}-0.2063 x+12.226
$$

where $\theta y$ is soil moisture content in $\%$ by volume and " $x$ " is the sensor reading in $\mathrm{mV}$.

Similarly, three pressure sensors were randomly selected for calibrating the depth of the water. Two flexible plastic tubes were attached to the pressure sensor. One tube was vented to the atmospheric pressure, and another was placed in a graduated glass cylinder. Water was gradually added to this graduated cylinder to increase the water level from 0.0 to $20 \mathrm{~cm}$, and the corresponding sensor reading of differential pressure was recorded. The graph of sensor readings versus water height for calibration is shown in Figure 3. The linear equation fitted to this graph is presented below in Equation (2), and it has a determination coefficient (R2) of 0.9891

$$
H=0.6072 x-292.48
$$

where, $H$ is the depth of water in $\mathrm{mm}$ and " $x$ " stands for sensor reading in $\mathrm{mV}$.

\section{Field Testing of WSN}

The field testing of the WSN's performance was carried out at three different locations: 1) Turfgrass Institute Guelph (ON) 2) Elora Research Station (ERS) located south of Elora (ON), and 3) Kettle-Creek paired watershed located within the southern boundary of the city of London (ON).

The soil moisture and pressure sensor readings obtained by the WSN were verified by the manual measurements in the field. The soil moisture level of the top

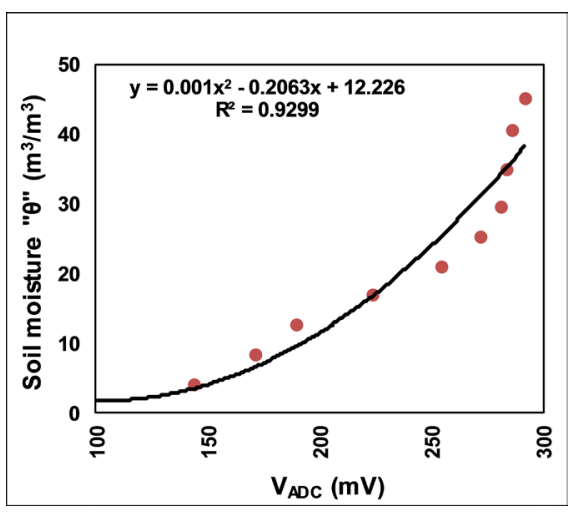

(a)

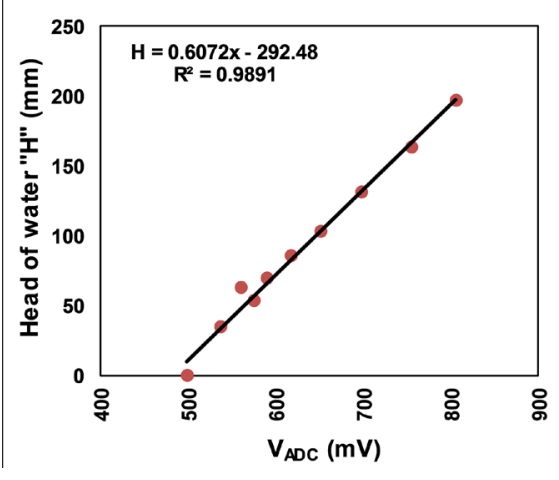

(b)

Figure 3. Calibration curves of soil moisture and pressure sensors. 
layer of soil was measured using a digital VG-200 soil moisture meter, and the height of water level above the V-notch was measured manually. Figure 4 show soil moisture levels and depth of water at the location of node \# 5 recorded by the WSN and manually for a storm occurred on 12 September 2011. Similarly, WSN readings of node \# 4 were verified manually on 27 December 2011 (Figure 5). The comparison confirmed the accurate functioning of the WSN system during field deployment.

\section{Field Data Collection}

After successful testing of the WSN system, data collection from a small agricultural study watershed of 21.62 ha located in the Elora Research Station (ERS) was carried out from September 2011 to July 2013. The ERS is situated at $43^{\circ} 39^{\prime}$ $\mathrm{N}$ and $80^{\circ} 25^{\prime} \mathrm{W}$, and it is about $20 \mathrm{~km}$ from Guelph (ON). The climate of Elora is temperate humid with average annual precipitation of $875 \mathrm{~mm}$ of which about $150 \mathrm{~mm}$ falls as snow. The elevation of this agricultural watershed ranges from 357 to $378 \mathrm{~m}$ with a gentle slope to slopes as steep as $22 \%$. The soil of the study

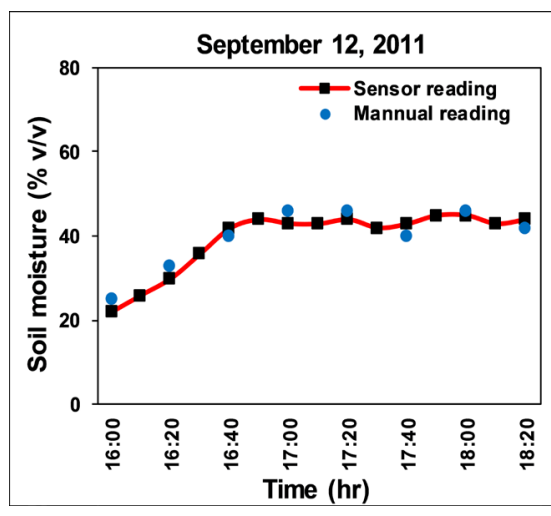

(a)

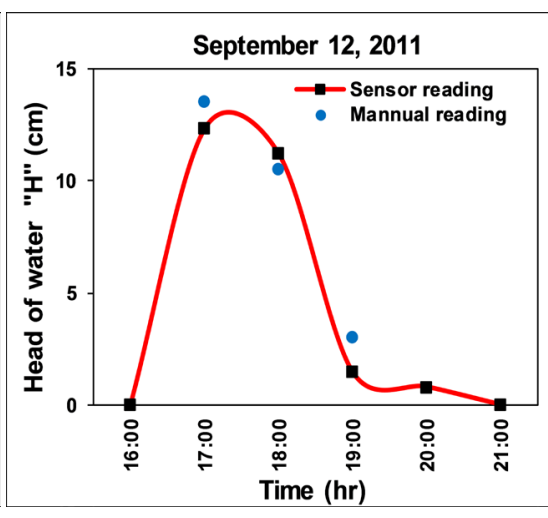

(b)

Figure 4. WSN and manual readings of soil moisture and pressure sensors on September 12, 2011.

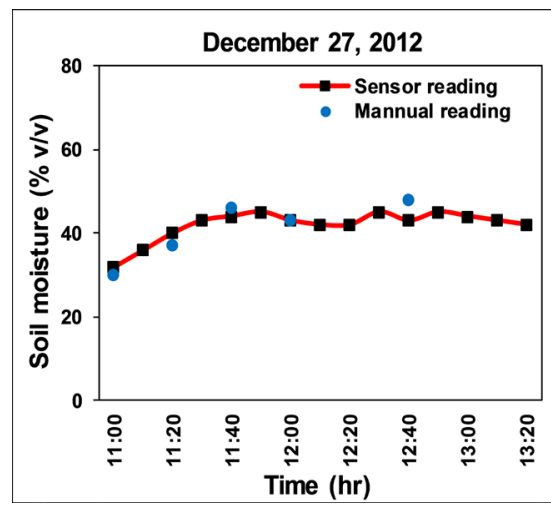

(a)

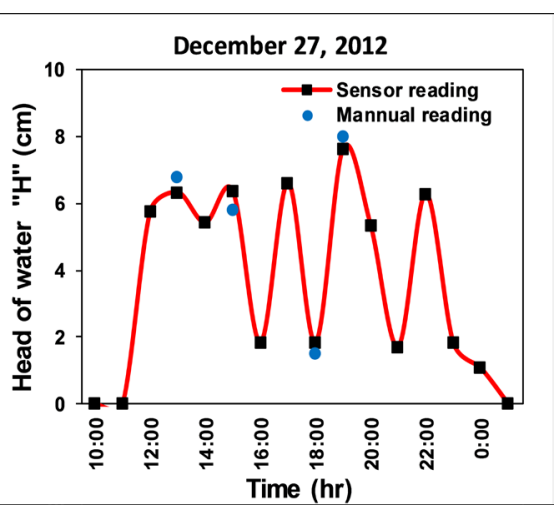

(b)

Figure 5. WSN and manual readings of soil moisture and pressure sensors on December 27, 2012. 
watershed is sandy loam belonging to hydrological soil group B with soil depth ranging from 0.60 to $0.90 \mathrm{~m}$ underlain by a restrictive layer. The entire watershed was under hay crop cultivation during the process of data collection.

The study watershed at ERS was divided into eight sub-watersheds using watershed delineating tool of ArcGIS. At the outlet of each sub-watershed, a V-notch weir with pressure sensor was installed to measure overland runoff. Soil moisture sensors were installed at the centroids of each sub-watersheds and near all eight outlet points. A total of 16 soil moisture sensors, $8 \mathrm{~V}$-notch weirs with pressure sensors, and six hopper nodes were installed in this study watershed. The watershed at ERS and the location of soil moisture sensors and V-notch weirs are shown in Figure 6. A base station node was attached to a computer with an internet connection and was stationed in a nearby private property in order to power the laptop. The $4.0 \mathrm{~V}$ rechargeable lead-acid batteries were used to power the nodes lasted for 40 to 45 days during the spring and fall seasons depending on weather conditions. During the summer, batteries persisted for more than 60 days.

The field computer was connected to the internet, and the computer software tools, LogMeIn, and Dropbox were used for real-time accessibility. The remote access tool LogMeIn was used to monitor and control the field computer. The field data collected were transferred and stored in Dropbox folders. Real-time access to the field computer offered the advantage of remotely monitoring the health and battery level of each node and sensors in the field. It was observed that rodents in the agricultural field were chewing and damaging the plastic tubes of pressure sensors and wires of soil moisture sensors. The real-time monitoring of field instruments helped timely repairing and replacing the damaged sensors/nodes. These visits ensured that the WSN system was working without interruptions and that no data was lost due to non-functional sensors/nodes. Real-time access also enabled to adjust the data sampling interval accordingly to

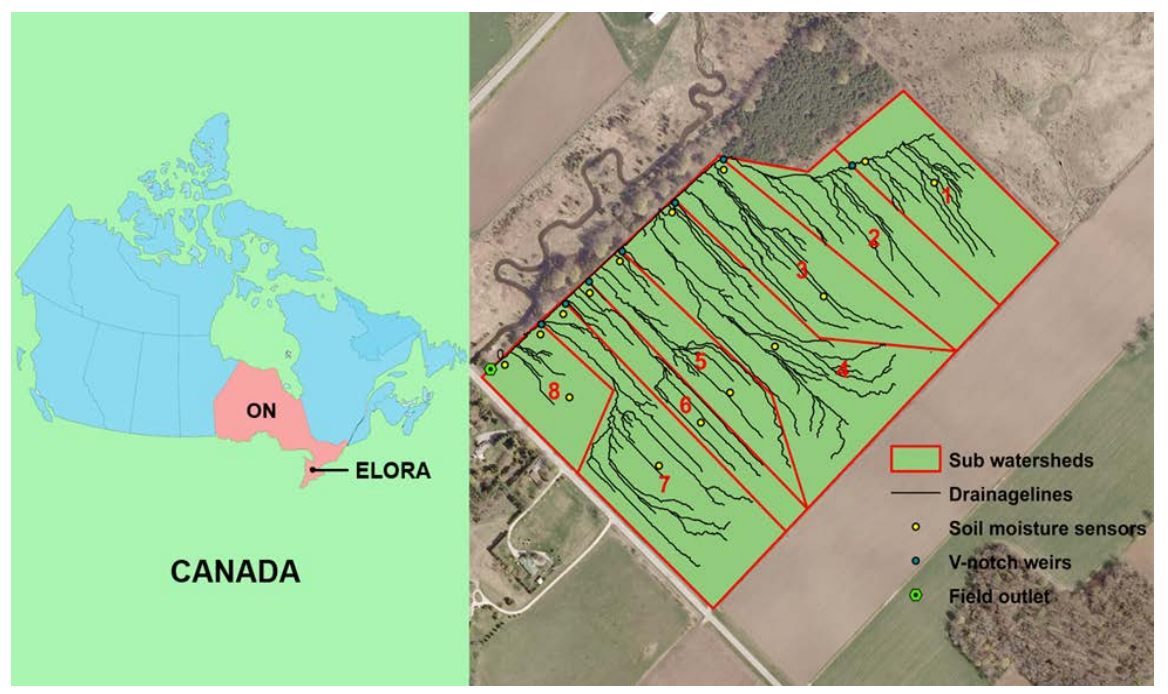

Figure 6. Layout of the study watershed at Elora (Ontario). 
wet or dry periods. Since the relevant data was to be collected during rainy periods, the sampling interval was shortened remotely during the dry weather. Furthermore, remote monitoring the system enabled to put the WSN in sleep mode during extended dry periods to conserve the battery power. This not only helped to conserve the battery life but also helped to avoid the accumulation of unnecessary data.

Soil moisture levels and runoff generated from eight sub-watersheds of the study area were monitored from September 2011 to July 2013, and data for 45 rainfall events were successfully collected. During the entire experimental period, WSN system worked efficiently, and no inconsistency was noticed in the performance of nodes due to variations in the climatic conditions. The readings of soil moisture sensors and pressure sensors were converted from $\mathrm{mV}$ to soil moisture percentage and water depth using calibration equations 1 and 2 respectively. The discharge $\left(\mathrm{m}^{3} / \mathrm{s}\right)$ corresponding to the water height above the bottom of the weir was determined using the V-notch equation. For each rainfall event, a flow hydrograph of individual sub-watershed segment was developed to compute the runoff. Rainfall and temperature data were collected from the ERS weather station located about $500 \mathrm{~m}$ from the study watershed.

The field measurements of a rainfall event dated 01, June 2012 are plotted in Figure 7. Rainfall started at 5.00 a.m., and the total rainfall for the event was 46.0 $\mathrm{mm}$. The initial soil moisture at the beginning of the rainfall was $14 \%$ and runoff initiated after 43 minutes when soil moisture reached $43 \%$ (saturation). The daytime maximum temperature was $13.7^{\circ} \mathrm{C}$, and the initial abstraction (Ia) of this rainfall event was $4.3 \mathrm{~mm}$. The peak discharges of $0.028,0.021$, and $0.020 \mathrm{~m} 3 / \mathrm{s}$ were recorded at $6.00 \mathrm{p} . \mathrm{m}$. at the outlets of sub-watershed 4, 7 and 1 respectively. For this rainfall event, a total of $2456 \mathrm{~m}^{3}$ of runoff was generated at the outlet of the watershed, and the runoff coefficient was $29.28 \%$.

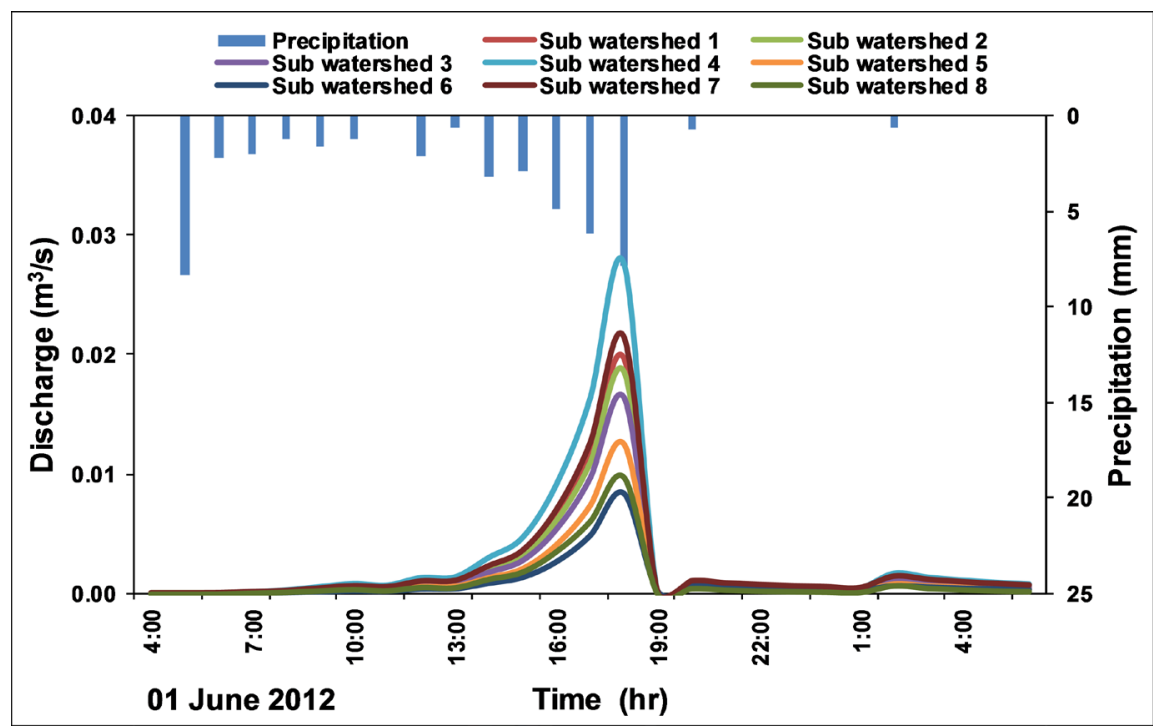

Figure 7. Field observations of rainfall and runoff event dated June 01, 2012. 
The continuously recorded data of soil moisture, rainfall, and temperature during September 2012 is shown in Figure 8. There were six major rainfall events including a maximum of $25.76 \mathrm{~mm}$ of rain recorded on 08 September 2012. The average soil moisture of the study watershed was about $14 \%$ at the beginning of the month and increased up to $42-44 \%$ during rainfall events. The graph also shows daily maximum and minimum temperatures during the month. The maximum temperature of $28.8^{\circ} \mathrm{C}$ was recorded on September 03, and the minimum of $0.6^{\circ} \mathrm{C}$ on September 24,2012 . The observations of rainfall, soil moisture, and temperature during the year 2012 are shown in Figure 9.

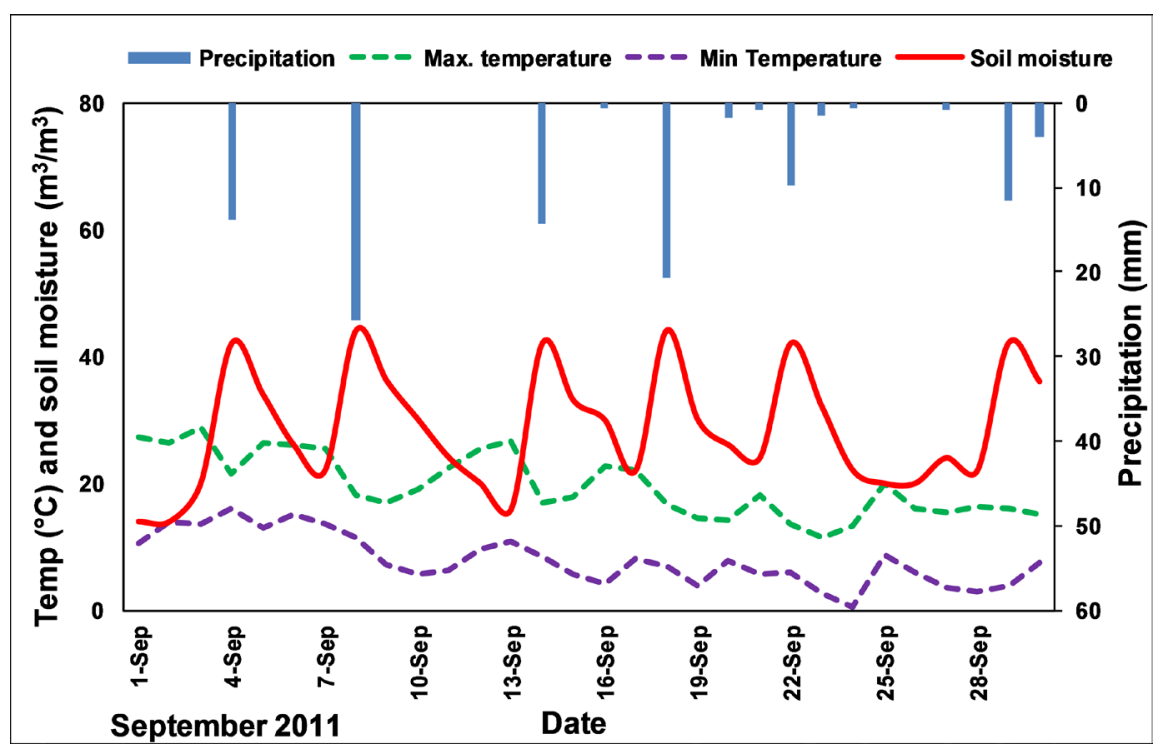

Figure 8. Field observations of rainfall, soil moisture, and temperature during September 2011.

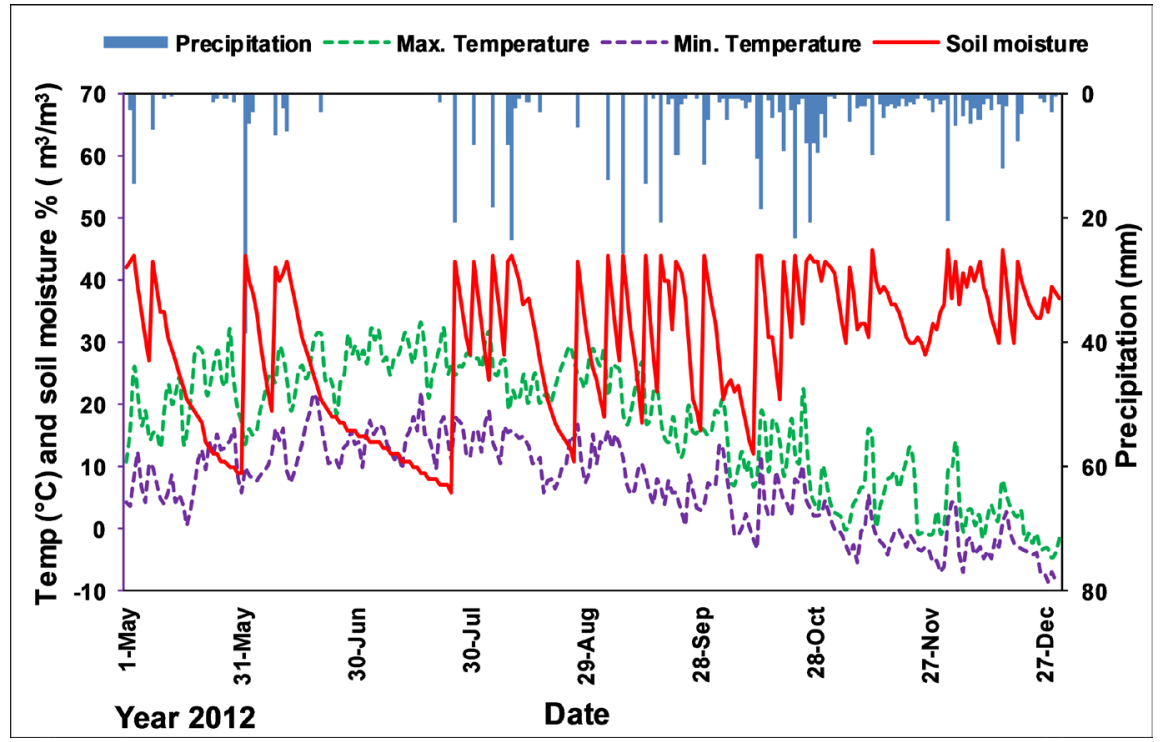

Figure 9. Field observations of rainfall, soil moisture, and temperature during the year 2012. 
The developed WSN system worked accurately with minimum maintenance. The field data of soil moisture and discharge for 10 rainfall events in the fall of 2011 were successfully recorded. During 2012, data for four spring events, 13 summer events, and 9 fall events were collected. During 2013, field data for 3 springs and 6 summer rainfall events were recorded. The collected data were used for the research project of Mapping and Modeling of Variable Source Areas in a Small Agricultural Watershed.

\section{Summary and Conclusions}

This study has provided an overview of the development of an integrated WSN system for monitoring the climatic and hydrologic parameters of a remotely located agricultural watershed. The designed WSN system comprised of an advanced wireless network technology, which together with the internet facilitated the data communication between the study site and the client in real-time. Low power consumption, along with its compact size and multiple sensors made it perfectly suitable for field application. The WSN system was calibrated in the laboratory and tested at three locations in southern Ontario, Canada. Field-scale testing demonstrated that the system is robust to work under adverse weather conditions, such as extreme variation in temperature, high winds, rain, and snow. The developed WSN system was used in a remote agricultural watershed near Elora (ON), where it successfully acquired, stored and transmitted real-time climatic and hydrological data. The WSN worked accurately with minimum maintenance and enabled continuous data collection for more than two years. The advantage of this system was that it could be accessed from anywhere by any computer connected to the internet. Remote data collection and maintenance considerably reduced the need for site visits, which significantly reduced the monitoring cost. Although this WSN system was tailored explicitly for mapping the VSAs in a small agricultural watershed, it is flexible for use in a variety of contexts.

\section{References}

[1] Freiberger, T.V., Sarvestani, S.S. and Atekwana, E. (2007) Hydrological Monitoring with Hybrid Sensor Networks. International Conference on Sensor Technologies and Applications, Valencia, 14-20 October 2007, 484-489.

https://doi.org/10.1109/SENSORCOMM.2007.4394967

[2] Pegram, G.G.S., Van Biljon, S. and Jordaan, J.M. (2009) Hydrological Data Acquisition Systems. Hydraulic Structure, Equipment and Water Data Acquisition Systems, 4,105 .

[3] Weng, S., Zhai, D., Yang, X. and Hu, X. (2017) A ZigBee Wireless Networking for Remote Sensing Applications in Hydrological Monitoring System. Proceedings of the SPIE, 10322, Article ID: 103221W.

[4] Oliveira, L.M.L. and Rodrigues, J.J.P.C. (2011) Wireless Sensor Networks: A Survey on Environmental Monitoring. Journal of Communications, 6, 143-151. https://doi.org/10.4304/jcm.6.2.143-151 
[5] Zhang, Z., Glaser, S.D., Bales, R.C., Conklin, M., Rice, R. and Marks, D.G. (2017) Technical Report: The Design and Evaluation of a Basin-Scale Wireless Sensor Network for Mountain Hydrology. Water Resources Research, 53, 4487-4498. https://doi.org/10.1002/2016WR019619

[6] Mainwaring, A., Culler, D., Polastre, J., Szewczyk, R. and Anderson, J. (2002) Wireless Sensor Networks for Habitat Monitoring. 1st ACM International Workshop on Wireless Sensor Networks and Applications, Atlanta, 28 September 2002, 88-97.

[7] Hart, J.K. and Martinez, K. (2006) Environmental Sensor Networks: A Revolution in the Earth System Science? Earth-Science Reviews, 78, 177-191. https://doi.org/10.1016/j.earscirev.2006.05.001

[8] Trubilowicz, J., Kan, C. and Markus, W. (2009) Viability of Motes for Hydrological Measurement. Water Resources Research, 45, W00D22. https://doi.org/10.1029/2008WR007046

[9] Mitake, K. and Ishihara, S. (2013) A Basic Study of Data Collection Ratio of Drifting Sensor Networks for Monitoring Waterways. 27 th International Conference on Advanced Information Networking and Applications Workshops (WAINA), Barcelona, 25-28 March 2013, 13-20. https://doi.org/10.1109/WAINA.2013.179

[10] Zhang, R., Guo, J., Zhang, L., Zhang, Y., Wang, L. and Wang, Q. (2011) A Calibration Method of Detecting Soil Water Content Based on the Information-Sharing in Wireless Sensor Network. Computers and Electronics in Agriculture, 76, 161-168. https://doi.org/10.1016/j.compag.2011.01.010

[11] Sarade, S.S., Joshi, A.C., Patil, S.S. and Shinde, A.N. (2012) Wireless Temperature Monitoring System Using Wireless Sensor Networks. International Journal of Advanced Research in Electronics and Communication Engineering, 1, 46-51.

[12] Karl, H. and Willig, A. (2007) Protocols and Architectures for Wireless Sensor Networks. John Wiley \& Sons, Hoboken.

[13] Alwadi, M.A. (2015) Energy Efficient Wireless Sensor Networks Based on Machine Learning. Ph.D. Thesis, University of Canberra, Canberra.

[14] Sharma, S., Bansal, R.K. and Bansal, S. () Issues and Challenges in Wireless Sensor Networks. International Conference on Machine Intelligence Research and Advancement IEEE, Katra, 21-23 December 2013, 58-62. https://doi.org/10.1109/ICMIRA.2013.18

[15] Shetty, N.R., Prasad, N.H. and Nalini, N. (2015) Emerging Research in Computing, Information, Communication and Applications. Springer. https://doi.org/10.1007/978-81-322-2550-8

[16] Pathak, N., Agrawal, P. and Gupta, R. (2014) Wireless Sensor Networks: A Survey. International Journal of Engineering and Technical Research, 247-251.

[17] Purohit, R. and Mathur, P. (2016) Role of Wireless Sensor Networks in Communication with Artificial Intelligence System. International Journal of Wireless and Mobile Communication for Industrial Systems, 3, 33-38. https://doi.org/10.21742/ijwmcis.2016.3.2.05

[18] Gutierrez, J.A., Callaway, E.H. and Barrett, R.L. (2004) Low-Rate Wireless Personal Area Networks: Enabling Wireless Sensors with IEEE 802.15.4. IEEE Standards Association.

[19] Yick, J., Mukherjee, B. and Ghosal, D. (2008) Wireless Sensor Network Survey. Computer Networks, 52, 2292-2330. https://doi.org/10.1016/j.comnet.2008.04.002

[20] Gilbert, E.P.K., Kaliaperumal, B. and Rajsingh, E.B. (2012) Research Issues in Wireless Sensor Network Applications: A Survey. International Journal of information 
and Electronics Engineering, 2, 702-706.

[21] Lewis, F.L. (2004) Wireless Sensor Networks. In: Cook, D.J. and Das, S.K., Eds., Smart Environments. Technologies, Protocols, and Applications, John Wiley, New York, 11-46.

[22] Mahgoub, I. and Ilyas, M. (2016) Sensor Network Protocols. CRC Press, Taylor and Francis Group, Boca Raton.

[23] Akyildiz, I.F., Su, W., Sankarasubramaniam, Y. and Cayirci, E. (2002) Wireless Sensor Networks: A Survey. Computer Networks, 38, 393-422. https://doi.org/10.1016/S1389-1286(01)00302-4

[24] Bogena, H.R., Huisman, J.A., Oberdorster, C. and Vereecken, H. (2007) Evaluation of a Low-Cost Soil Water Content Sensor. Journal of Hydrology, 344, 32-42. https://doi.org/10.1016/j.jhydrol.2007.06.032

[25] Prabhu, S.R.B., Pradeep, M. and Gajendran, E. (2017) Monitoring Climatic Conditions Using Wireless Sensor Networks. A Multidisciplinary Journal of Scientific Research \& Education, 3, 179-184.

[26] Jing, W. and Tingting, L. (2015) Application of Wireless Sensor Network in Yangtze River Basin Water Environment Monitoring. Control and Decision Conference, 27, 5981-5985. https://doi.org/10.1109/CCDC.2015.7161882

[27] Khairnar, P.P., Gaikwad, D.V., Kale, S.R., Madane, M.T. and Giri, M.B. (2016) Wireless Sensor Network Application in Agriculture for Monitoring Agriculture Production Process. International Journal of Advanced Research in Computer Engineering \& Technology, 5, 2278-1323.

[28] Burrell, J., Brooke, T. and Beckwith, R. (2004) Vineyard Computing: Sensor Networks in Agricultural Production. IEEE Pervasive Computing, 3, 38-45. https://doi.org/10.1109/MPRV.2004.1269130

[29] Verma, R. (2013) A Survey on Wireless Sensor Network Applications, Design Influencing Factors \& Types of Sensor Network. International Journal of Innovative Technology and Exploring Engineering, 3, 2278-3075.

[30] Barrenetxea, G., Ingelrest, F., Schaefer, G., Vetterli, M., Couach, O. and Parlange, M. (2008) Sensor Scope: Out-of-the-Box Environmental Monitoring. IEEE Computer Society, 332-343. https://doi.org/10.1109/IPSN.2008.28

[31] Kerkez, B., Glaser, S.D., Bales, R.C. and Meadows, M.W. (2012) Design and Performance of a Wireless Sensor Network for Catchment-Scale Snow and Soil Moisture Measurements. Water Resources Research, 48, 9. https://doi.org/10.1029/2011WR011214

[32] Karthik, S. and Ashok Kumar, A. (2015) Challenges of Wireless Sensor Networks and Issues Associated with Time Synchronization. International Journal of Advanced Networking and Applications, 19-23.

[33] Tarannum, S. (2010) Energy Conservation Challenges in Wireless Sensor Networks: A Comprehensive Study. Wireless Sensor Network, 2, 483-491. https://doi.org/10.4236/wsn.2010.26060

[34] Pour, N.K. (2015) Energy Efficiency in Wireless Sensor Networks. PhD Thesis, Engineering and Information Technology, University of Technology, Sydney.

[35] Mohanty, P., Panigrahi, S., Sarma, N. and Satapathy, S.S. (2010) Security Issues in Wireless Sensor Network Data Gathering Protocols: A Survey. Journal of Theoretical and Applied Information Technology, 13, 14-27.

[36] Marfievici, R., Murphy, A.L., Pietro Picco, G., Ossi, F. and Cagnacci, F. (2013) How 
Environmental Factors Impact Outdoor Wireless Sensor Networks: A Case Study. IEEE 10 th International Conference on Mobile Ad-Hoc Sensor and System, Hangzhou, 14-16 October 2013, 565-573.

[37] Panjabi, K. (2015) Mapping and Modeling of Variable Source Areas in a Small Agricultural Watershed. PhD Thesis, School of Engineering, University of Guelph, Guelph.

[38] Poret, S. (2009) Implementation of a Low Power Wireless Sensor Network for Watershed Monitoring. Master's Dissertation, University of Guelph, Guelph.

[39] Chapi, K. (2009) Monitoring and Modeling of Runoff Generating Areas in a Small Agriculture Watershed. PhD Thesis, School of Engineering, University of Guelph, Guelph.

[40] Turon, M. (2005) Mote-View: A Sensor Network Monitoring and Management Tool. Embedded Networked Sensors, Sydney, 31 May 2005, 11-17.

https://doi.org/10.1109/EMNETS.2005.1469094 